\title{
Comparison of Functional Group Selective Ion-Molecule Reactions of Trimethyl Borate in Different Ion Trap Mass Spectrometers
}

\author{
Steve C. Habicht, ${ }^{1,2}$ Nelson R. Vinueza, ${ }^{1}$ Lucas M. Amundson, ${ }^{1}$ Hilkka I. Kenttämaa ${ }^{1}$ \\ ${ }^{1}$ Department of Chemistry, Purdue University, Brown Building, 560 Oval Drive, West Lafayette, IN 47906, USA \\ ${ }^{2}$ Center for Naval Analysis, 4825 Mark Center Drive, Alexandria, VA 22311, USA
}

\begin{abstract}
We report here a comparison of the use of diagnostic ion-molecule reactions for the identification of oxygen-containing functional groups in Fourier-transform ion cyclotron resonance (FTICR) and linear quadrupole ion trap (LQIT) mass spectrometers. The ultimate goal of this research is to be able to identify functionalities in previously unknown analytes by using many different types of mass spectrometers. Previous work has focused on the reactions of various boron reagents with protonated oxygen-containing analytes in FTICR mass spectrometers. By using a LQIT modified to allow the introduction of neutral reagents into the helium buffer gas, this methodology has been successfully implemented to this type of an ion trap instrument. The products obtained from the reactions of trimethyl borate (TMB) with various protonated analytes are compared for the two instruments. Finally, the ability to integrate these reactions into LC-MS experiments on the LQIT is demonstrated.
\end{abstract}

Key words: Ion-molecule reactions, Functional groups, FTICR, LQIT, LTQ, CAD, HPLC/MS

\section{Introduction}

$\mathrm{T}$ andem mass spectrometry (MS/MS) is a powerful tool for obtaining structural information for organic compounds directly in complex mixtures [1]. Among the multiple flavors of tandem mass spectrometry, collisionactivated dissociation (CAD) of isolated ions is the most commonly employed method for structural elucidation [2]. However, in some instances, particularly in quadrupole ion trap mass spectrometers due to their low-energy multiplecollision conditions, CAD may lead to a mass spectrum dominated by structurally uninformative fragment ions, such as those formed by $\mathrm{H}_{2} \mathrm{O}$ or $\mathrm{NH}_{3}$ loss [3]. Hence, CAD experiments do not always provide unambiguous information on the elemental connectivity of an ion [4-7]. This

Correspondence to: Hilkka I. Kenttämaa; e-mail: hilkka@purdue.edu forces the analyst to use additional analytical techniques, such as nuclear magnetic resonance (NMR) and Fourier transform infrared spectroscopy (FTIR), for complete structural characterization. Unfortunately, these experiments usually require relatively pure analytes. Alternatively, the analyst may choose to compare the MS/MS spectra of the analyte and an authentic reference compound that has been purchased or synthesized. However, this approach takes time and hence detracts from the inherent speed of the MS analysis [4-6].

MS/MS utilizing ion-molecule reactions has proven to be a powerful tactic for structural elucidation, as evidenced by several recent reviews on the subject [8-10]. Ion-molecule reactions can be fast, efficient, and highly specific, properties which often are paramount to molecular characterization experiments. Ion-molecule reactions have been used for isomer differentiation [11-14], functional group identification [15-20], and detailed structural elucidation [21-23]. 
Further, the use of well-characterized ion-molecule reactions has found a niche for the fast detection of specific compound classes $[24,25]$. In addition, ion-molecule reactions have been demonstrated to complement CAD in some cases where the latter method alone did not provide the level of characterization required [26, 27].

Gas-phase ion-molecule reactions of neutral boron compounds with protonated analytes have been demonstrated to facilitate the identification of the presence and counting of various oxygen-containing functional groups in a Fouriertransform ion cyclotron resonance (FTICR) mass spectrometer [28-31]. The general mechanism proposed for the diagnostic reaction of trimethyl borate (TMB) with a protonated oxygen-containing analyte is shown in Scheme $\mathbf{1 .}$ The characteristic product ion of the reaction with TMB is observed at an $\mathrm{m} / \mathrm{z}$ value 72 thomson (Th) higher than the protonated analyte, which corresponds to addition of the TMB molecule to the analyte followed by elimination of methanol from the adduct. The product ion is easy to identify due to the unique isotope ratio of boron $(25 \%$ ${ }^{10} \mathrm{~B}$ relative to $\left.{ }^{11} \mathrm{~B}\right)$. The product ion was only observed for oxygen-containing analytes; for example, nitrogencontaining analytes are generally unreactive toward this boron reagent. Hence, the reaction can be used to identify the presence of an oxygen-functionality. The number of the oxygen functionalities can often be determined by counting the methanol molecules lost upon the reactions of the protonate analyte with one or several TMB molecules. However, these experiments were executed by using specialized, obsolete instrumentation (i.e., dualcell FTICR).

In addition to FTICR, quadrupole ion traps (QIT) offer the versatility of tandem-in-time MS/MS experiments, and have been widely used to study ion-molecule reactions [12, 13, 22, 23, 32-34]. More recently, linear quadrupole ion traps (LQIT), which are characterized by an improved trapping capability and sensitivity compared to the QIT [35], have also been used to explore such reactions [36, 37]. We present here a systematic comparison of the performance of a modified LQIT to that of a dual-cell FTICR mass spectrometer for studying gas-phase ion-molecule reactions. Further, the products of the ion-molecule reactions have been subjected to CAD to produce fragments that provide information for the exact nature of the oxygen-containing functional groups present in the analytes. Finally, the implementation of the method on the HPLC time scale is demonstrated.

\section{Experimental}

\section{Materials}

HPLC grade water was purchased from Burdick and Jackson Morristown, NJ, USA and HPLC grade acetonitrile was purchased from Mallinckrodt St. Louis, MO, USA. All other chemicals used were purchased from Sigma-Aldrich (St. Louis, $\mathrm{MO}, \mathrm{USA}$ ) and used as received without further purification.

\section{FTICR Mass Spectrometry}

FTICR experiments were performed in a Nicolet (Madison, WI, USA) FTMS 2000 dual-cell FTICR mass spectrometer equipped with a 3-T superconducting magnet. The instrument contained a tungsten filament for producing ions in situ via either electron ionization (EI) or chemical ionization (CI), depending on ionization conditions. The dual-cell instrument contained two cubic $(5.08 \mathrm{~cm} \times 5.08 \mathrm{~cm} \times 5.08 \mathrm{~cm})$ cells separated by a conductance limit. The cells are identical and experiments could be performed in either one. Each cell was differentially pumped to achieve a nominal baseline pressure of $1 \times 10^{-9}$ Torr. The two trapping plates and the conductance limit each contained a 2-mm hole in the center to allow the electron beam produced by the filament to pass through both cells. This allowed ionization to take place in either cell. In addition, the conductance limit orifice allowed for the transfer of ions between the two cells. All three trapping plates were maintained at $+2.0 \mathrm{~V}$ during the experiments except for ion transfer, during which the conductance limit was grounded. The instrument contained multiple inlets for sample introduction, including pulsed valves for gases, variable leak valves for volatile samples, and a thermal heated desorption probe for solid samples. A Sun Microsystems Redwood Shores, CA, USA SPARK 5 workstation (Unix-based SunOS operating system) running Odyssey 4.2 software was used for instrumental control, data acquisition and data procession.

The protonated analytes were generated via chemical ionization (CI), either by using methanol as a CI reagent or by using "self-CI," in which the analyte of interest was used as the CI reagent. This was accomplished by allowing the molecular ion and fragment ions formed from the $\mathrm{CI}$ reagent upon electron ionization (40-70 eV electron energy, $7.0 \mu \mathrm{A}$ filament current, $10-100 \mathrm{~ms}$ ionization time) to react (1-5 s) with the neutral analyte (nominal pressure $\sim 4 \times 10^{-8}$ Torr) in one cell of the instrument. The protonated analyte was transferred into the other cell and was allowed to cool for about $1 \mathrm{~s}$ by IR emission and collisions with $\operatorname{Ar}$ (nominal

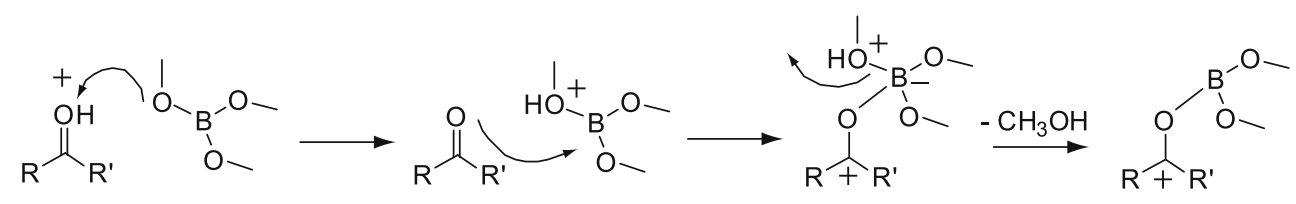

Scheme 1. 
peak pressure $\sim 10^{-5}$ Torr). The ion was isolated using stored waveform inverse Fourier transform [38] (SWIFT) excitation pulses to eject unwanted ions, and then allowed to react (100 ms-200 s) with TMB present at $\sim 2 \times 10^{-8}$ Torr. In some cases, the reaction products were isolated and subjected to sustained off-resonance irradiated collisionactivated dissociation [39] (SORI-CAD) to probe their structures. This was accomplished by using an excitation pulse with a frequency $1 \mathrm{kHz}$ higher than the cyclotron frequency of the ion in the presence of Ar (nominal peak pressure $\sim 10^{-5}$ Torr) for $300-600 \mathrm{~ms}$.

Following reactions, all ions were excited for detection using chirp excitation ( $46 \mathrm{kHz}$ to $2.7 \mathrm{MHz}$ (corresponding to $m / z$ 17-1000), $\left.124 \mathrm{~V}_{p-p}, 3200 \mathrm{~Hz} / \mu \mathrm{s}\right)$ and detected using an $8 \mathrm{MHz}$ sampling rate. All transients, recorded as $64 \mathrm{k}$ data points, were subjected to Hanning apodization and one zerofill prior to Fourier transformation. All mass spectra shown are an average of at least 10 scans.

\section{LQIT Mass Spectrometry}

The experiments were performed in a Finnigan (San Jose, CA, USA) LTQ linear quadrupole ion trap (LQIT) mass spectrometer equipped with an atmospheric pressure chemical ionization (APCI) source and modified to perform ionmolecule reactions [36]. Sample solutions were prepared at analyte concentrations from 0.01 to $1 \mathrm{mg} / \mathrm{mL}\left(10^{-5}\right.$ to $10^{-}$ ${ }^{3} \mathrm{M}$ ) in either $100 \% \mathrm{CH}_{3} \mathrm{CN}$ or $50 / 50(\mathrm{vol} / \mathrm{vol}) \mathrm{H}_{2} \mathrm{O} /$ $\mathrm{CH}_{3} \mathrm{CN}$. The solutions were infused at $5 \mu \mathrm{L} / \mathrm{min}$ by using the integrated syringe drive of the LTQ and combined via a tee with $50 / 50$ ( $\mathrm{vol} / \mathrm{vol}) \mathrm{H}_{2} \mathrm{O} / \mathrm{CH}_{3} \mathrm{CN}$ delivered from a Finnigan (San Jose, CA, USA) Surveyor MS Pump Plus at $100 \mu \mathrm{L} / \mathrm{min}$. The resulting mixture was infused into the APCI source to generate the protonated analytes of interest. Typical APCI conditions were: discharge current, $5.0 \mu \mathrm{A}$; vaporizer temperature, $450{ }^{\circ} \mathrm{C}$; sheath gas $\left(\mathrm{N}_{2}\right)$ flow, 50 (arbitrary units); auxiliary gas flow $\left(\mathrm{N}_{2}\right), 20$ (arbitrary units); sweep gas flow $\left(\mathrm{N}_{2}\right), 5$ (arbitrary units); and capillary temperature, $250{ }^{\circ} \mathrm{C}$. Voltages for the ion optics were optimized for each analyte by using the tune feature of the LTQ Tune Plus interface.

Neutral TMB was introduced into the helium buffer gas line by using an external reagent mixing manifold, as described previously [36]. Briefly, TMB was introduced into the manifold via a syringe drive at $30 \mu \mathrm{L} /$ hour where it was diluted into a measured flow of helium $(100-500 \mathrm{~mL} / \mathrm{min})$ to give mixing ratios of $\sim 10^{4}$ to $\sim 10^{5}$ (He/reagent). The syringe port and surrounding area of the manifold was heated to $\sim 70{ }^{\circ} \mathrm{C}$ to ensure rapid evaporation of TMB into the flow of helium. Based on the relative flows of the TMB and helium, and accounting for differential effusion from the trap, the typical pressure of TMB present during the experiments is estimated as $10^{-7}$ to $10^{-6}$ Torr.

The experiments were performed using the advanced scan features of the LTQ Tune Plus interface. The analyte ion was isolated using a $2-3 \mathrm{~m} / \mathrm{z}$ window (full width) and a q-value of 0.25 , then allowed to react with TMB for $10 \mathrm{~ms}$ to $10 \mathrm{~s}$ before being ejected from the trap and detected. CAD experiments involved isolation of the reaction product by using a 4-6 $\mathrm{m} / \mathrm{z}$ window and the application of an appropriate activation voltage (generally $10 \%-30 \%$ of the normalized collision energy (NCE), as defined by the LTQ Tune Plus interface) for $30 \mathrm{~ms}$. Xcalibur 2.0 software was used for both data acquisition and processing. All mass spectra shown are an average of at least 10 scans.

\section{High Performance Liquid Chromatography (HPLC)}

HPLC experiments were performed using a Finnigan Surveyor HPLC system, consisting of an autosampler, thermostatted column compartment, and quarternary pump. The analytes were separated on a Thermo Aquasil $\mathrm{C}_{18}(100 \mathrm{~mm} \times 2.1 \mathrm{~mm}$ i.d., $5 \mu \mathrm{m}$ ) column at a column temperature of $35^{\circ} \mathrm{C}$. Mobile phase A consisted of a $0.1 \%$ formic acid in $\mathrm{H}_{2} \mathrm{O}$ and mobile phase $\mathrm{B}$ consisted of $0.1 \%$ formic acid in $\mathrm{CH}_{3} \mathrm{CN}$. A $5 \mu \mathrm{L}$ injection of each sample was loaded onto the column. Separation was accomplished at a flow rate of $300 \mu \mathrm{L} / \mathrm{min}$ using the following linear gradient: $0 \mathrm{~min}, 10 \% \mathrm{~B} ; 10 \mathrm{minp}, 30 \% \mathrm{~B}$.

\section{Results and Discussion}

\section{Ion Trap Comparison}

In the experiments discussed here, the analyte of interest was ionized and isolated in one side of a dual cell FTICR instrument and then transferred into the other side (which contained TMB) for ion-molecule reactions. In the LQIT instrument, an analogous experiment should be possible by generating the ion of interest in an API source, transferring it into the ion trap and isolating it there, and examining its reactions with TMB that has been leaked into the trap with the helium buffer gas [36]. Hence, the initial experiments focused on demonstrating that these ion-molecule reactions occur similarly in the LQIT mass spectrometer as in the FTICR.

Figure 1 shows an example of a mass spectrum measured for the diagnostic reaction of TMB with protonated ethyl benzoate in the FTICR and LQIT mass spectrometers. In both spectra, the expected reaction product ion is clearly visible at $\mathrm{m} / \mathrm{z} 223$. This ion corresponds to addition of TMB to the analyte followed by the loss of methanol. The derivatization product is easy to identify in each mass spectrum due to the unique boron isotope ratio $\left(25 \%{ }^{10} \mathrm{~B}\right.$ relative to ${ }^{11} \mathrm{~B}$ ). The only difference between the two mass spectra is the inherently higher resolution of the FTICR instrument, which can be seen by comparison of the insets of Figure 1. Isolation of the reaction product ion followed by $\mathrm{CAD}$ in both instruments produced a dominant fragment ion of $\mathrm{m} / \mathrm{z} 105$, which corresponds to a loss of $\mathrm{CH}_{3} \mathrm{CH}_{2} \mathrm{OB}$ $\left(\mathrm{OCH}_{3}\right)_{2}$ from the ionic reaction product. The probable reaction sequence is shown in Scheme 2.

Several of the analytes used in the previous FTICR experiments were studied in the LQIT in order to compare 

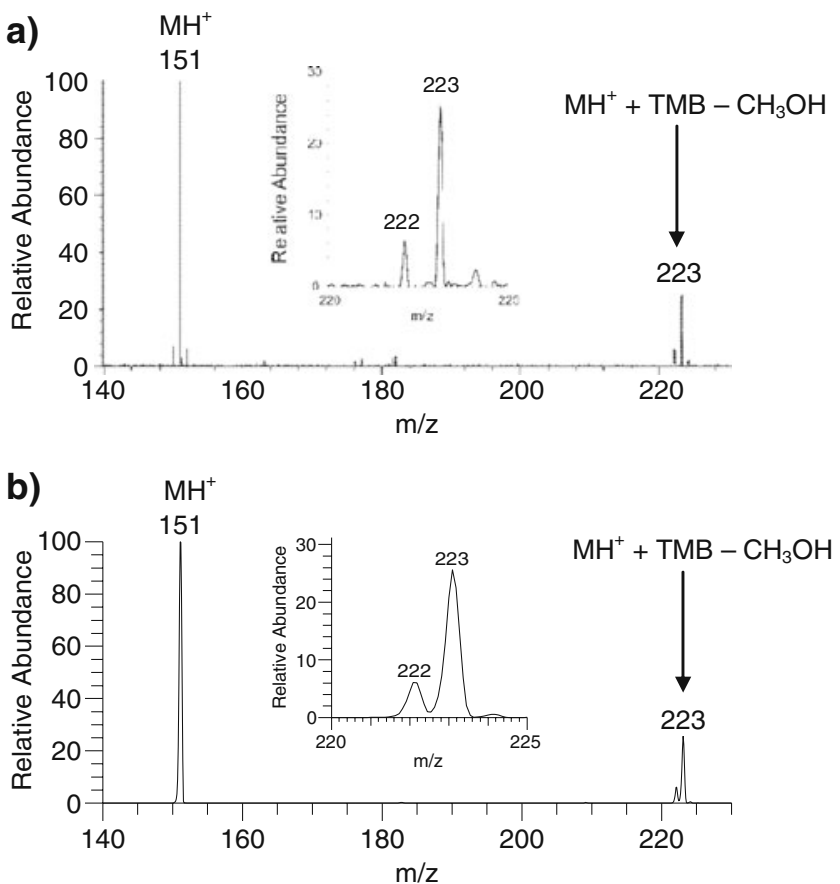

Figure 1. Positive-ion mass spectra measured for ethyl benzoate after ionization, isolation of the protonated molecule and exposure to TMB in (a) FTICR and (b) LQIT mass spectrometers. The boron-containing product ions are easily identified by the unique boron isotope ratio (inset)

the performance of the two ion trap mass spectrometers. In every case, similar results were obtained in the two instruments, despite the significantly different reaction conditions. For example, the nominal pressure of TMB present during the ion-molecule reactions was 1 to 2 orders of magnitude greater in the LQIT than in the FTICR. As expected, this led to much shorter reaction times in the LQIT instrument. For example, the mass spectrum shown in Figure $1 \mathrm{~b}$ was acquired after a $0.5 \mathrm{~s}$ reaction time in the LQIT, as opposed to the mass spectrum shown in Figure 1a, which was acquired after a $5 \mathrm{~s}$ reaction time in the FTICR. Yet, in each case, the expected derivatization product ion was observed and it was the dominant product ion. However, in addition to the expected product ion, an additional product ion was usually observed in the LQIT that has a $\mathrm{m} / \mathrm{z}$ value 14 Th less than the expected product ion (for examples, see Figure 2 and Figure 6). This ion is believed to be a product of the reaction of the protonated analyte with partially hydrolyzed TMB, in which one of the methoxy groups has been replaced by a hydroxy group (likely upon reaction with adventitious water). Boric acid esters are known to be susceptible to hydrolysis in the presence of water [40], and a previous report has acknowledged that adventitious water may be present in this type of a system [41].

\section{CAD of TMB-Derivatized Analytes}

Since the same derivatization product was observed for all oxygen-containing analytes in both instruments, this reaction alone does not provide information on the type of the oxygen-containing functionality present. In the FTICR mass spectrometer, the diagnostic product ions were transferred into the other side of the dual-cell reaction chamber, isolated, and structural information was obtained via H/D exchange reactions and/or CAD [28-30]. Here, CAD was used in the LQIT to examine the type of information obtained in this mass spectrometer on the identity of the functional groups present in oxygen-containing analytes (Table 1). The following sections summarize the results obtained for several simple analytes that were protonated, isolated and allowed to react with TMB to form the diagnostic product ion, which was then subjected to CAD in the two ion trap mass spectrometers.

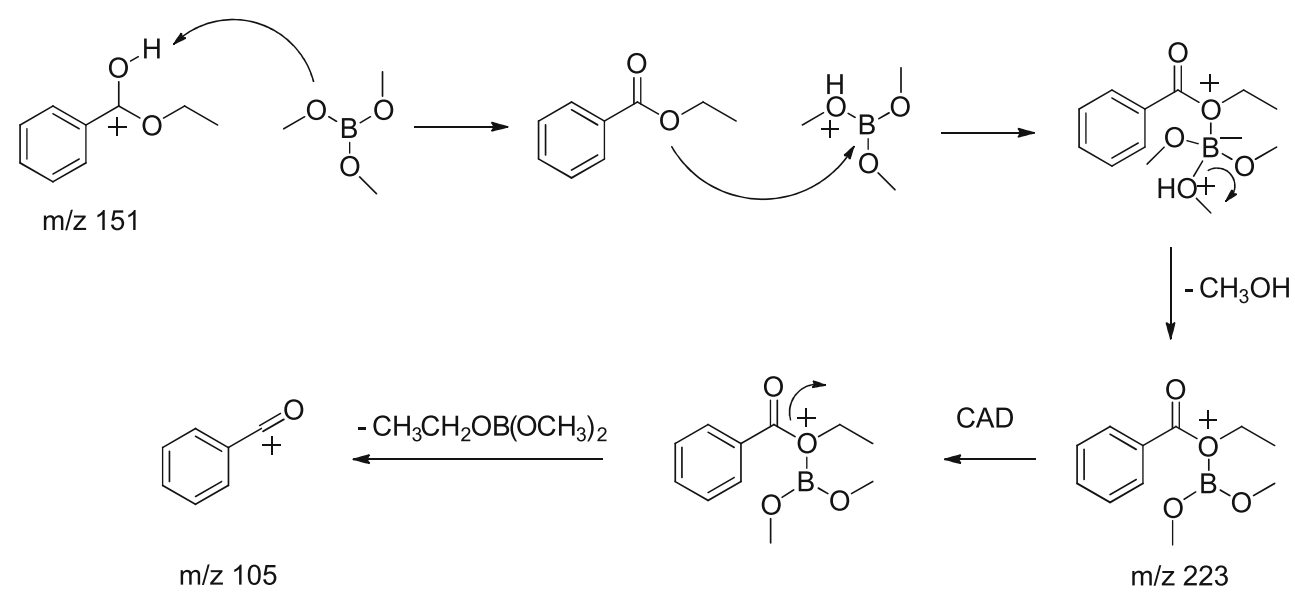

Scheme 2. 
Table 1. Diagnostic product ions observed for protonated oxygen-containing analytes upon exposure to TMB in the LQIT mass spectrometer, and their characteristic CAD fragment ions

\begin{tabular}{|c|c|c|c|c|}
\hline $\begin{array}{l}\text { Compound } \\
\text { Type }^{a}\end{array}$ & \multicolumn{2}{|c|}{$\begin{array}{c}\text { Analyte } \\
\left(\mathrm{m} / \mathrm{z} \text { of }[\mathrm{M}+\mathrm{H}]^{+}\right)\end{array}$} & $\begin{array}{l}\text { Ion-Molecule } \\
\text { Reaction } \\
\text { Product(s) }\end{array}$ & $\begin{array}{l}\text { Characteristic } \\
\text { Fragment } \\
\text { Ion(s) }\end{array}$ \\
\hline \multirow[t]{2}{*}{$\begin{array}{l}\text { Alcohol } \\
\mathrm{R}-(\mathrm{OH})_{\mathrm{n}}\end{array}$} & $\mathrm{n}=1$ & $\begin{array}{l}\text { Phenol (95) } \\
\text { Benzyl Alcohol (109) } \\
\text { 2-Napthenol (145) }\end{array}$ & $\begin{array}{l}+\mathrm{TMB}- \\
\mathrm{CH}_{3} \mathrm{OH}\end{array}$ & $\begin{array}{l}\text { Product }- \\
\mathrm{O}=\mathrm{BOCH}_{3}\end{array}$ \\
\hline & $\begin{array}{l}\mathrm{n}=4 \\
\mathrm{n}=5 \\
\mathrm{n}=6\end{array}$ & $\begin{array}{l}\text { Erythritol (123) } \\
\text { Xylitol (153) } \\
\text { Mannitol (183) }\end{array}$ & $\begin{array}{l}+\mathrm{mTMB}_{-}^{-} \\
\mathrm{nCH}_{3} \mathrm{OH}^{\mathrm{b}}\end{array}$ & $\mathrm{NM}^{\mathrm{C}}$ \\
\hline & \multicolumn{2}{|c|}{$\begin{array}{l}\text { Propylene Oxide (59) } \\
\text { Tetrahydrofuran (73) } \\
\text { Tetrahydropyran (87) }\end{array}$} & $\begin{array}{l}+\mathrm{TMB}^{-} \\
\mathrm{CH}_{3} \mathrm{OH}\end{array}$ & $\begin{array}{l}\text { Product- } \\
\text { HO-B }\left(\mathrm{OCH}_{3}\right)_{2}\end{array}$ \\
\hline Aldehyde & \multicolumn{2}{|c|}{$\begin{array}{c}\text { Benzaldehyde (107) } \\
\text { 2-Chlorobenzadehyde (141) } \\
\text { 4-Biphenylcarboxaldehyde } \\
\text { (183) } \\
\text { 2-Fluorenecarboxaldehyde } \\
\text { (195) }\end{array}$} & $\begin{array}{l}+\mathrm{TMB}^{-} \\
\mathrm{CH}_{3} \mathrm{OH}\end{array}$ & $\begin{array}{l}\text { Product }- \\
\mathrm{O}=\mathrm{BOCH} \mathrm{H}_{3} \\
\text { Product }- \\
\mathrm{O}=\mathrm{BOCH}_{3}- \\
\mathrm{CH}_{2} \mathrm{O}\end{array}$ \\
\hline \multirow[t]{2}{*}{$\begin{array}{l}\text { Ketone } \\
{ }_{\mathrm{R}}^{\mathrm{O}} \\
\mathrm{R}^{\prime}\end{array}$} & \multicolumn{2}{|c|}{$\begin{array}{l}\text { 2-Pentanone (87) } \\
\text { 2-Heptanone (115) } \\
\text { 4-Heptanone (115) } \\
\text { 2-Octanone (129) }\end{array}$} & $\begin{array}{l}+\mathrm{TMB}- \\
\mathrm{CH}_{3} \mathrm{OH}\end{array}$ & $\begin{array}{c}\text { Product - } \\
\left(\mathrm{R}^{\prime}-\mathrm{H}\right)\end{array}$ \\
\hline & \multicolumn{2}{|c|}{$\begin{array}{l}\text { Acetophenone (121) } \\
\text { 9-Fluorenone (181) } \\
\text { Benzophenone (183) }\end{array}$} & $\begin{array}{l}+\mathrm{TMB}- \\
\mathrm{CH}_{3} \mathrm{OH}\end{array}$ & $\begin{array}{l}\text { Product - } \\
\mathrm{CH}_{3} \mathrm{OH} \\
\text { Product }- \\
\mathrm{O}=\mathrm{BOCH}_{3} \\
\text { Product }- \\
\mathrm{O}=\mathrm{BOCH}_{3}- \\
\mathrm{CH}_{2} \mathrm{O}\end{array}$ \\
\hline $\begin{array}{l}\text { Carboxylic } \\
\text { Acid }\end{array}$ & \multicolumn{2}{|c|}{$\begin{array}{l}\text { Butanoic Acid (89) } \\
\text { Hexanoic Acid (117) } \\
\text { Heptanoic Acid (131) } \\
\text { Benzoic Acid (123) } \\
\text { Phenylacetic Acid (137) }\end{array}$} & $\begin{array}{l}+\mathrm{TMB}^{-} \\
\mathrm{CH}_{3} \mathrm{OH}\end{array}$ & $\begin{array}{l}\text { Product- } \\
\text { HO-B }\left(\mathrm{OCH}_{3}\right)_{2} \\
\text { Product- } \\
\mathrm{HO}-\mathrm{B}\left(\mathrm{OCH}_{3}\right)_{2} \\
-\mathrm{CO}\end{array}$ \\
\hline $\mathrm{R}^{\prime} \mathrm{N}^{-\mathrm{R}}$ & \multicolumn{2}{|c|}{$\begin{array}{l}\text { Methyl Isobutyrate (103) } \\
\text { Methyl Valerate (117) } \\
\text { Ethyl Valerate }(131) \\
\text { Methyl Benzoate }(137) \\
\text { Ethyl Benzoate (151) }\end{array}$} & $\begin{array}{l}+{ }^{\mathrm{TMB}-} \\
\mathrm{CH}_{3} \mathrm{OH}\end{array}$ & $\begin{array}{c}\text { Product- } \\
\text { R'O-B }\left(\mathrm{OCH}_{3}\right)_{2}\end{array}$ \\
\hline 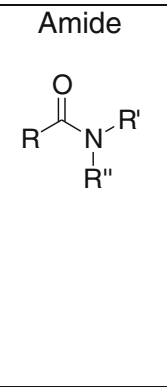 & \multicolumn{2}{|c|}{$\begin{array}{c}\text { Acetamide (60) } \\
\text { Propionamide (74) } \\
\text { Butyramide (88) } \\
\text { Benzamide (122) } \\
\text { N-Methylacetamide (74) } \\
\text { N-Methylpropionamide (88) } \\
\text { N-Ethylacetamide (88) } \\
\text { N-Phenylformamide (122) } \\
\text { N,N-Dimethylacetamide (88) } \\
\text { N,N-Dimethylpropionamide } \\
\text { (102) }\end{array}$} & $\begin{array}{l}+\mathrm{TMB}- \\
\mathrm{CH}_{3} \mathrm{OH}\end{array}$ & $\begin{array}{l}\text { Product }- \\
\mathrm{O}=\mathrm{C}=(\mathrm{R}-\mathrm{H}) \\
\text { Product }- \\
\mathrm{CH}_{3} \mathrm{OH}\end{array}$ \\
\hline $\begin{array}{l}\text { Amine } \\
\mathrm{R}_{\mathbf{N}^{-} \mathrm{R}^{-}} \\
1 \\
\mathrm{R}^{\prime \prime}\end{array}$ & \multicolumn{2}{|c|}{$\begin{array}{c}\text { Diethylamine (74) } \\
\text { Triethylamine (101) } \\
\text { Aniline (94) }\end{array}$} & No Reaction & -- \\
\hline
\end{tabular}

${ }^{a} \mathrm{R}, \mathrm{R}^{\prime}, \mathrm{R}^{\prime \prime}=$ Different alkyl groups

${ }^{\mathrm{b}}$ Several reaction products were observed in the mass spectrum of each polyol.

${ }^{\mathrm{c}} \mathrm{NM}=$ Not Measured

${ }^{\mathrm{d}}$ TMB-derivatized benzoic acid did not undergo a loss of CO upon CAD.

${ }^{\mathrm{e}}$ TMB-derivatized benzamide forms a primary fragment ion corresponding to the benzoyl cation. 


\section{Alcohols}

Several protonated analytes containing the hydroxy functionality were tested in the LQIT. Protonated alcohols react with TMB to form the diagnostic product ion (see Scheme 1 for the likely mechanism). Upon CAD, these product ions were found to yield a characteristic fragment ion via loss of $\mathrm{O}=\mathrm{BOCH}_{3}$ (Table 1) (possibly as shown for an aldehyde in Scheme 3). Several protonated polyols were also examined in the LQIT. Previously, TMB was used to count the number of hydroxy groups in protonated polyols by counting the number of methanol losses upon reactions with TMB molecules in a FTICR mass spectrometer [29]. The number of TMB molecules that have added to the analyte can be confirmed by the characteristic boron isotope ratio. Protonated polyols were found to form the same ionic products upon reactions with TMB in the LQIT. For example, the mass spectrum collected for the reaction of protonated xylitol with TMB is shown in Figure 2. An expanded view of the peak at $m /$ $z 305$, which corresponds to $\left[\mathrm{MH}^{+}+3 \mathrm{TMB}-5 \mathrm{CH}_{3} \mathrm{OH}\right]^{+}$, displays the characteristic isotope ratio indicative of the presence of three boron atoms. The theoretical isotope pattern for this ion is shown for confirmation (simulated using the isotope pattern simulation feature of the Xcalibur software).

\section{Ethers}

Several protonated cyclic ethers were allowed to react with TMB in the LQIT and found to yield a product ion analogous to that formed by protonated alcohols, in agreement with the results obtained earlier in the FTICR [30]. Upon $\mathrm{CAD}$, the diagnostic product ion of these reactions fragments by loss of $\mathrm{HOB}\left(\mathrm{OCH}_{3}\right)_{2}$ (Table 1). This neutral loss is different from that observed upon CAD of derivatized alcohols (see above); thus, these two functional groups can be distinguished.

\section{Aldehydes}

Several protonated aromatic aldehydes were examined in the LQIT and FTICR. Protonated aldehydes react with TMB to form the diagnostic product ion in both instruments. Upon $\mathrm{CAD}$, the diagnostic product ion of the aldehydes fragments by loss of $\mathrm{O}=\mathrm{BOCH}_{3}$, just as derivatized aromatic alcohols (Scheme 3; a mechanism for this loss has been published earlier [29]). However, it also fragments via loss of both $\mathrm{O}=\mathrm{BOCH}_{3}$ and $\mathrm{CH}_{2} \mathrm{O}$ (Table 1; Scheme 3), which allows the distinction of derivatized aldehydes from derivatized aromatic alcohols.

\section{Ketones}

Several protonated analytes containing a keto functional group were tested in the LQIT. As for the analytes discussed above, protonated ketones form the diagnostic product ion upon exposure to TMB. Upon CAD, the product ion of protonated aliphatic ketones forms a characteristic fragment ion that corresponds to a loss of the larger of the two alkyl chains of the ketone minus a hydrogen atom, likely either as an alkene or a cyclic alkane. This fragment ion was also observed earlier in the FTICR [30]. This fragmentation allows aliphatic ketones to be differentiated from the other functionalities discussed above. In contrast, the product ion of protonated aromatic ketones dissociates via loss of $\mathrm{O}=\mathrm{BOCH}_{3}$ and loss of both $\mathrm{O}=\mathrm{BOCH}_{3}$ and $\mathrm{CH}_{2} \mathrm{O}$, just as derivatized aromatic aldehydes (see Scheme 3 ). However, the product ion of aromatic ketones also fragments via loss of $\mathrm{CH}_{3} \mathrm{OH}$ (possibly as shown in Scheme 4 for amides). Thus, these functional groups can be distinguished. For diaryl ketones (e.g., benzophenone), elimination of the methanol molecule must involve an aromatic proton.

\section{Carboxylic Acids}

Several protonated analytes containing a carboxylic acid group were tested in the LQIT. Protonated carboxylic acids react with TMB to form the diagnostic product ion. The product ion dissociates via loss of $\mathrm{HOB}\left(\mathrm{OCH}_{3}\right)_{2}$ upon $\mathrm{CAD}$. This is the same fragmentation that was observed for TMB-derivatized ethers (see above). However, the derivatized carboxylic acids also fragment via a consecutive loss of CO (Table 1). This observation may allow distinction between carboxylic acids and ethers (see Figure 3). These results are consistent with those obtained in the FTICR instrument [29]. An exception is the product ion of benzoic acid - upon CAD, the loss of $\mathrm{HOB}$ $\left(\mathrm{OCH}_{3}\right)_{2}$ leads to the formation of an especially stable benzoyl cation that does not fragment by $\mathrm{CO}$ loss.

\section{Esters}

Several protonated ester molecules were examined in both the LQIT and FTICR. The diagnostic product ion is formed

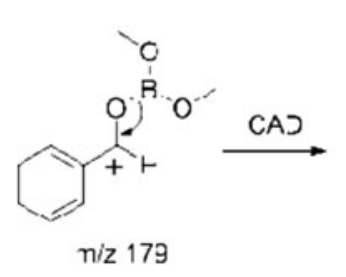

niz 179

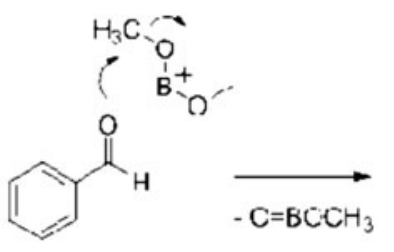

Scheme 3.

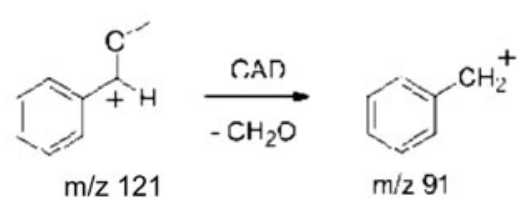

$\mathrm{m} / \mathrm{z} 121$ 

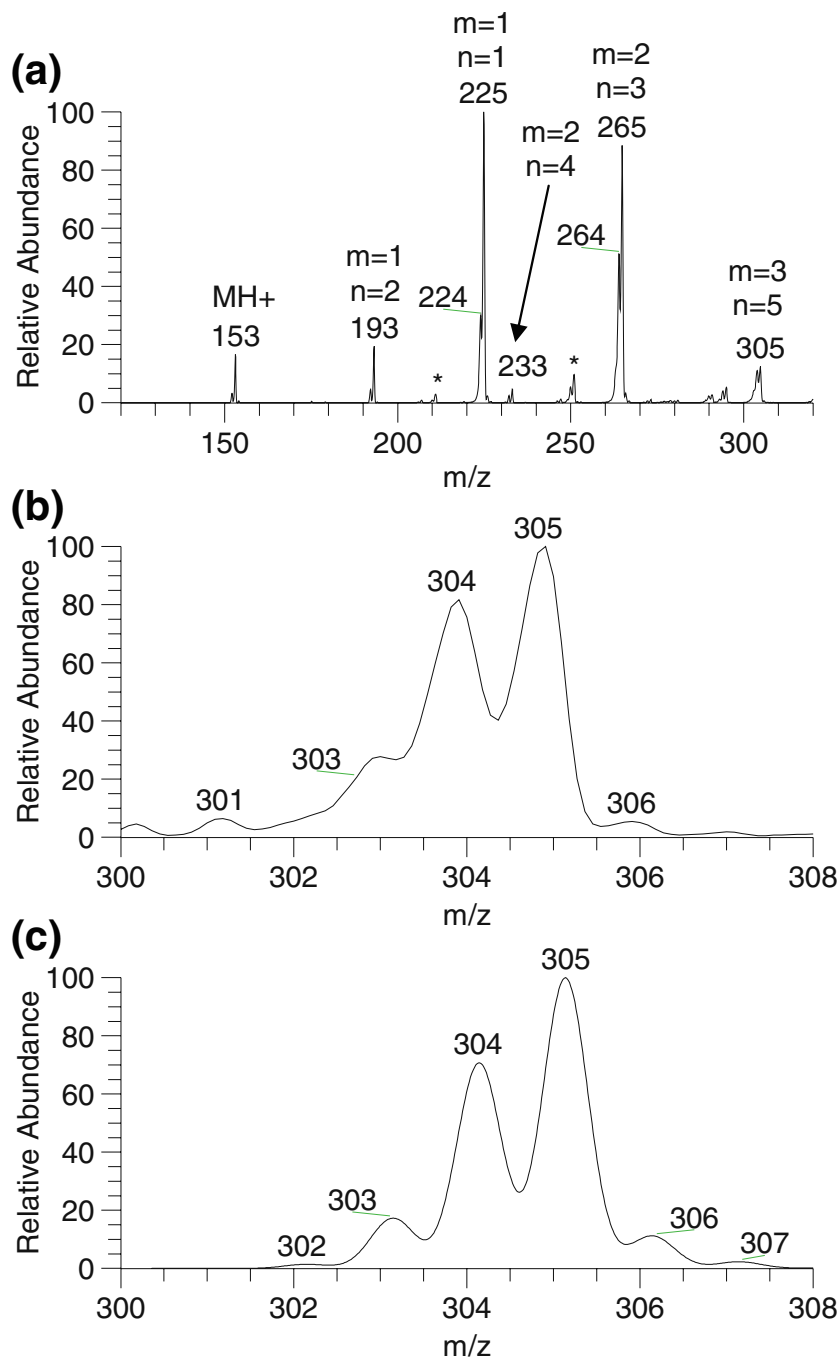

Figure 2. (a) Mass spectra obtained for xylitol after ionization, isolation of the protonated analyte and exposure to TMB in the LQIT. The peaks are labeled as $\left[\mathrm{MH}^{+}+\mathrm{mTMB}-\right.$ $\left.\mathrm{nCH}_{3} \mathrm{OH}\right]^{+}$( ${ }^{*}$ denotes secondary products in which one of the methoxy groups of TMB has been exchanged with a hydroxyl group). (b) Expanded view displaying the isotope pattern of the product ion $\left[\mathrm{MH}^{+}+3 \mathrm{TMB}-5 \mathrm{CH}_{3} \mathrm{OH}\right]^{+}(\mathrm{m} / \mathrm{z}$ 305). (c) Theoretical isotope pattern for the same product ion

upon exposure to TMB. Upon CAD, the diagnostic product ion is characterized by a loss of $\mathrm{ROB}\left(\mathrm{OCH}_{3}\right)_{2}$, where $\mathrm{R}$ equals the O-alkyl chain of the ester (Scheme 2). This finding allows differentiation of esters from all the other analytes discussed above. The same results were obtained in both mass spectrometers.

\section{Amides}

Several protonated analytes containing an amido group were tested in the LQIT. Protonated primary and secondary amides form the expected product ion upon exposure to TMB, just like in FTICR [29]. Hence, these amides cannot be differentiated from solely oxygen-containing analytes based on these reactions. Protonated tertiary amides also form the expected reaction product, albeit very slowly. Upon $\mathrm{CAD}$, the product ion of protonated amides forms two fragment ions (Figure 4), one via elimination of methanol (possibly as shown in Scheme 4), and the other via elimination of ketene. Scheme 4 also shows the formation of an interfering ion-molecule reaction product via proton transfer to a second TMB molecule followed by addition and loss of methanol (analogous to the mechanism in Scheme 1 [28-30]). Since this reaction was not observed without collisional activation, the first reaction step, proton transfer from the first ion-molecule product to TMB, is probably endothermic.

The above results differ slightly from the fragmentation behavior reported in previous work [29], where derivatized amides were concluded to fragment via loss of $\mathrm{O}=\mathrm{B}-\mathrm{R}$, where $\mathrm{R}$ equals the acyl alkyl group of the amide. In the present work, this reaction was reinvestigated and determined to involve loss of $\mathrm{O}=\mathrm{C}=(\mathrm{R}-\mathrm{H})$ from the derivatized amide (based on the observation of boron isotopes for the fragment ion; Figure 4b), which produces an ion isobaric to that postulated previously. An exception was observed for derivatized benzamide, which forms a stable benzoyl cation upon $\mathrm{CAD}$ rather than dissociating via ketene loss.

\section{Amines}

Protonated amines did not form the diagnostic product ion upon exposure to TMB, even at the elevated pressures present in the LQIT. This finding is consistent with the results previously obtained by using FTICR [28-30], and demonstrates that the TMB reaction is indeed characteristic for oxygen-containing analytes, including amides.

\section{$L C-M S^{n}$}

A benefit of implementing the above methodology to the LQIT instrument is the ease at which this mass spectrometer can be coupled with HPLC, thus enabling LC-MS ${ }^{n}$ experiments. Since the ion-molecule reactions discussed above are fast (vide supra), analytes may be successfully ionized, isolated, derivatized and fragmented as they elute from the LC column. To test this possibility, a four-component $1 \mathrm{mM}$ (equimolar) mixture of monofunctional aromatic analytes (aniline, benzoic acid, benzaldehyde, and methyl benzoate) was prepared and injected onto the LC column of an HPLC/ LQIT. The LQIT was set to automatically isolate the protonated molecule of each analyte (one after the other), allow them to react with TMB for $30 \mathrm{~ms}$, and then isolate the product ion and subject it to $\mathrm{CAD}$ (i.e., $\mathrm{MS}^{3}$ ).

The resulting total ion chromatogram (TIC) and selected ion chromatograms (SIC) obtained for the protonated molecule of each analyte in this mixture are shown in Figure 5. Each of the analytes displays a single, intense peak corresponding to the protonated molecule. Figure 6 shows the $\mathrm{MS}^{2}$ spectra measured after isolation of each protonated molecule and 

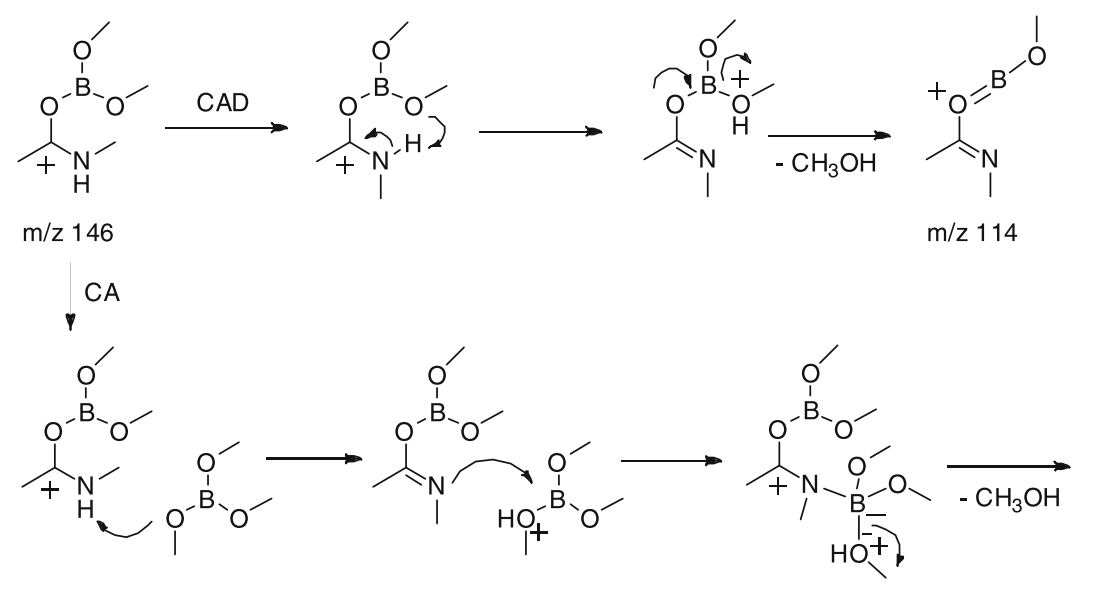<smiles>COB(OC)OB(OC)N(C)[C@H](C)OB(OC)OC</smiles>

$\mathrm{m} / \mathrm{z} 218$

Scheme 4.

exposure to TMB for $30 \mathrm{~ms}$. As expected, no product ion was observed for the reaction of TMB with protonated aniline, while the remaining three components display a large peak corresponding to the product ion. Further probing of the ionmolecule reaction products by CAD (spectra not shown) produced the expected fragment ions indicative of each analyte's functional group (vide supra).

Since the ion-molecule reactions tested here are fast $[29,30]$, the experiment can be conducted on the same time scale as a traditional LC-MS ${ }^{3}$ experiment (based on
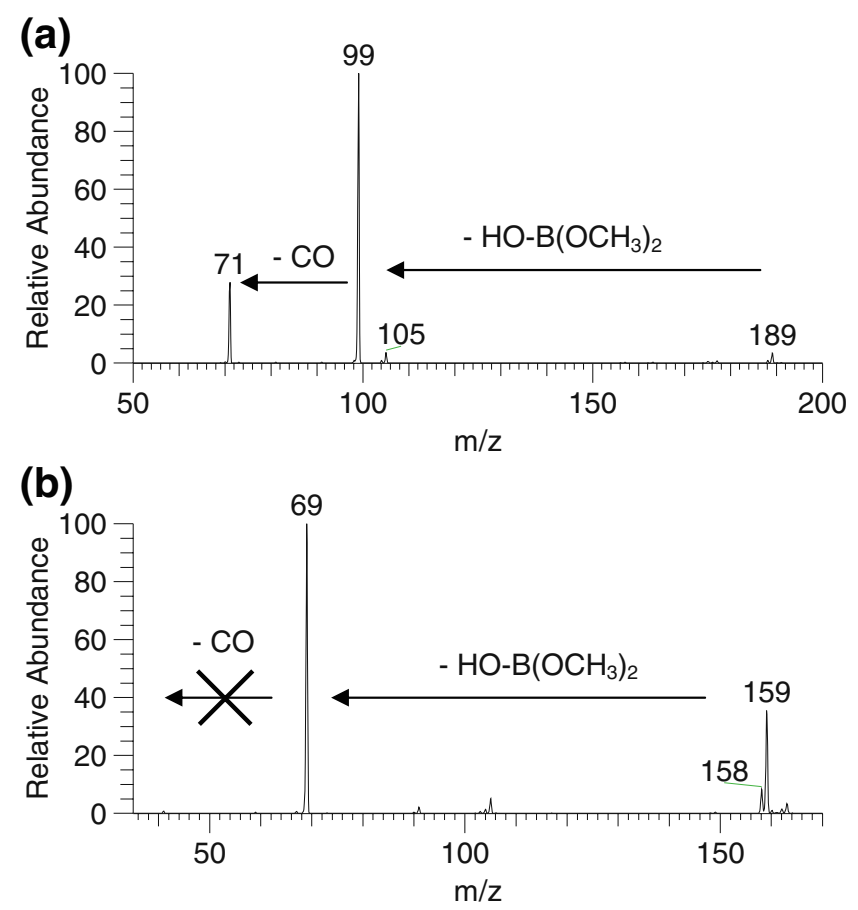

Figure 3. CAD mass spectra obtained for the isolated product ion formed in the reaction of TMB with protonated (a) hexanoic acid ( $\mathrm{m} / \mathrm{z} 189)$ and (b) tetrahydropyran ( $\mathrm{m} / \mathrm{z} 159)$ in the LQIT. Although both reaction products dissociate primarily via loss of $\mathrm{HOB}\left(\mathrm{OCH}_{3}\right)_{2}$, only the carboxylic acid analyte undergoes a further loss of $\mathrm{CO}$
CAD). Each of the spectra shown in Figure 6 is the average of approximately 30 scans; thus, even when examining an ion-molecule reaction requiring a reaction time of $1 \mathrm{~s}$ (a factor of 30 slower than the reactions studied here), several $\mathrm{MS}^{3}$ spectra may still be collected across a chromatographic peak.

(a)
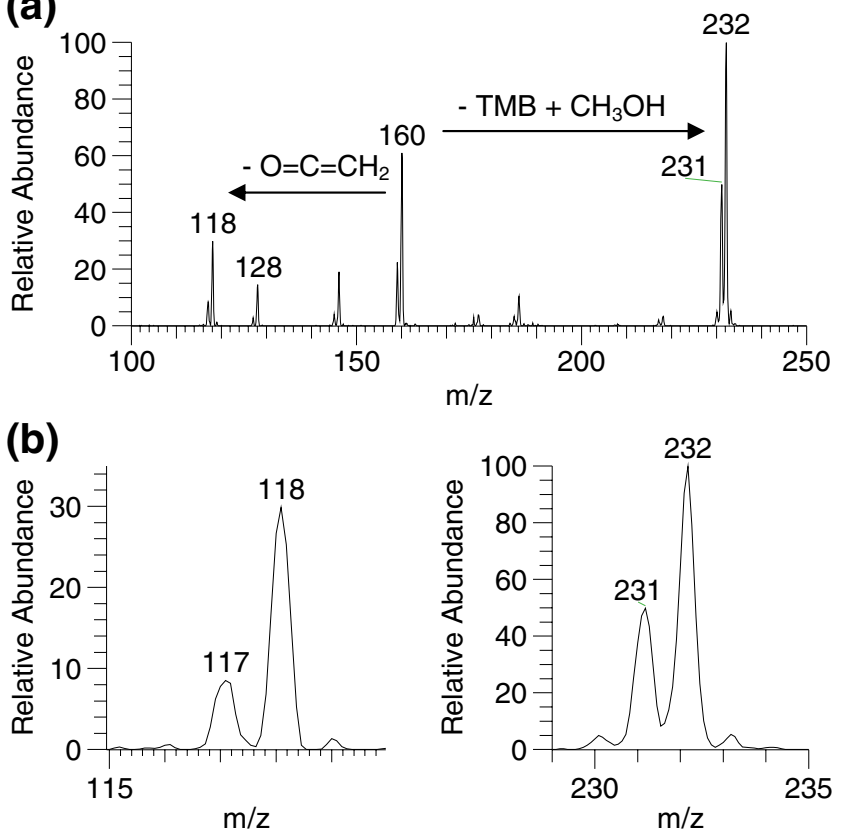

Figure 4. (a) A CAD mass spectrum obtained for the isolated, singly derivatized product ion $(\mathrm{m} / \mathrm{z} 160)$ formed from the reaction of protonated $\mathrm{N}$-ethylacetamide and TMB in the LQIT. The most abundant fragment ion $(\mathrm{m} / \mathrm{z}$ 118) corresponds to a loss of $\mathrm{O}=\mathrm{C}=\mathrm{CH}_{2}$. An interfering ionmolecule reaction is also observed: the most abundant product ion corresponds to reaction of the singly derivatized product ion with TMB, leading to a second derivatization $(\mathrm{m} / \mathrm{z}$ 232). (b) Expanded views of peaks at $\mathrm{m} / \mathrm{z} 118$ and 232, indicating the presence of one and two boron atoms, respectively 


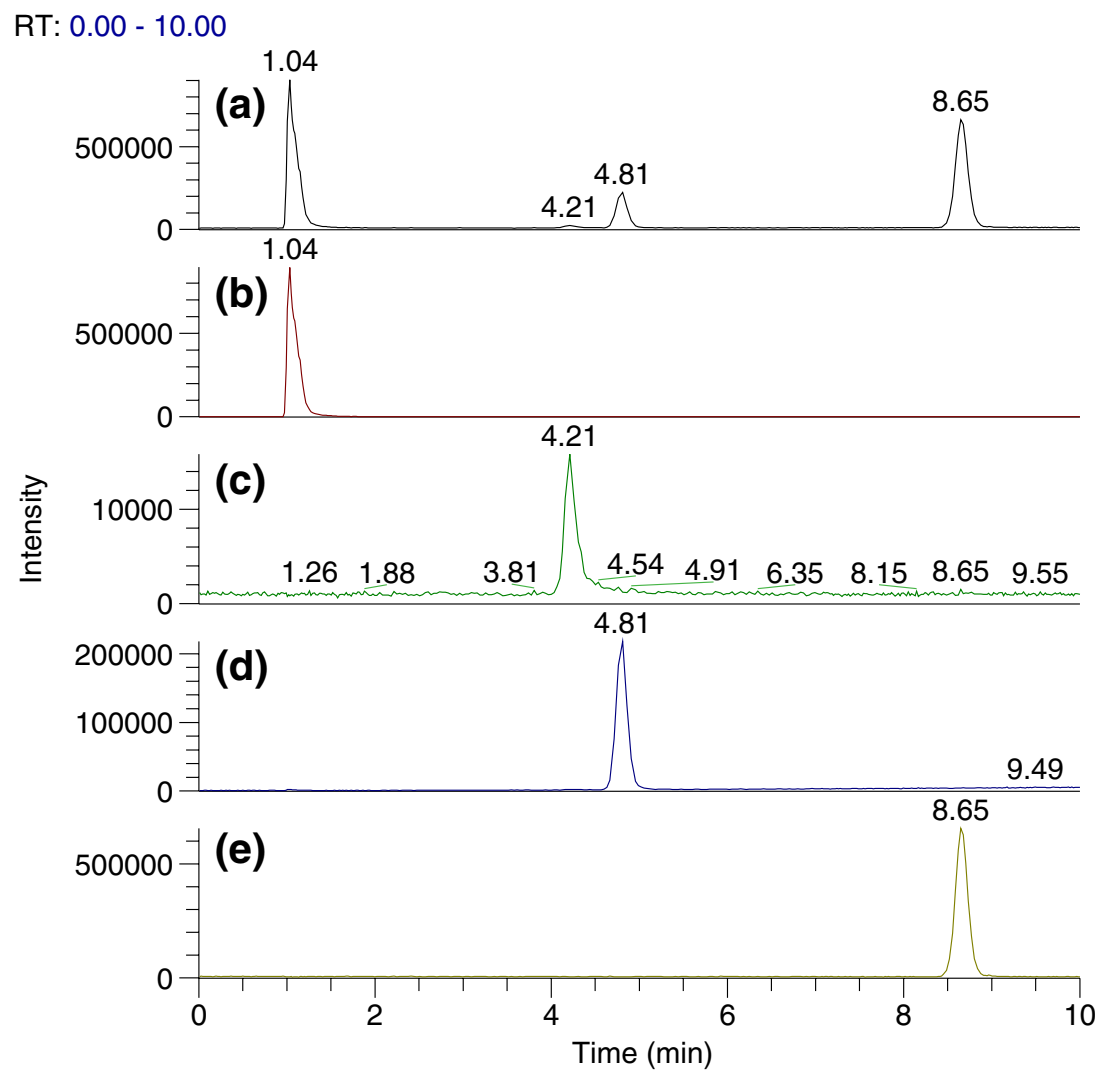

Figure 5. Total ion chromatogram (a) and selected ion chromatograms [(b), $\mathrm{m} / \mathrm{z}$ 94; (c), $\mathrm{m} / \mathrm{z} \mathrm{123}$; (d), $\mathrm{m} / \mathrm{z}$ 107; (e) $\mathrm{m} / \mathrm{z}$ 137] measured for a four component mixture during separation by HPLC

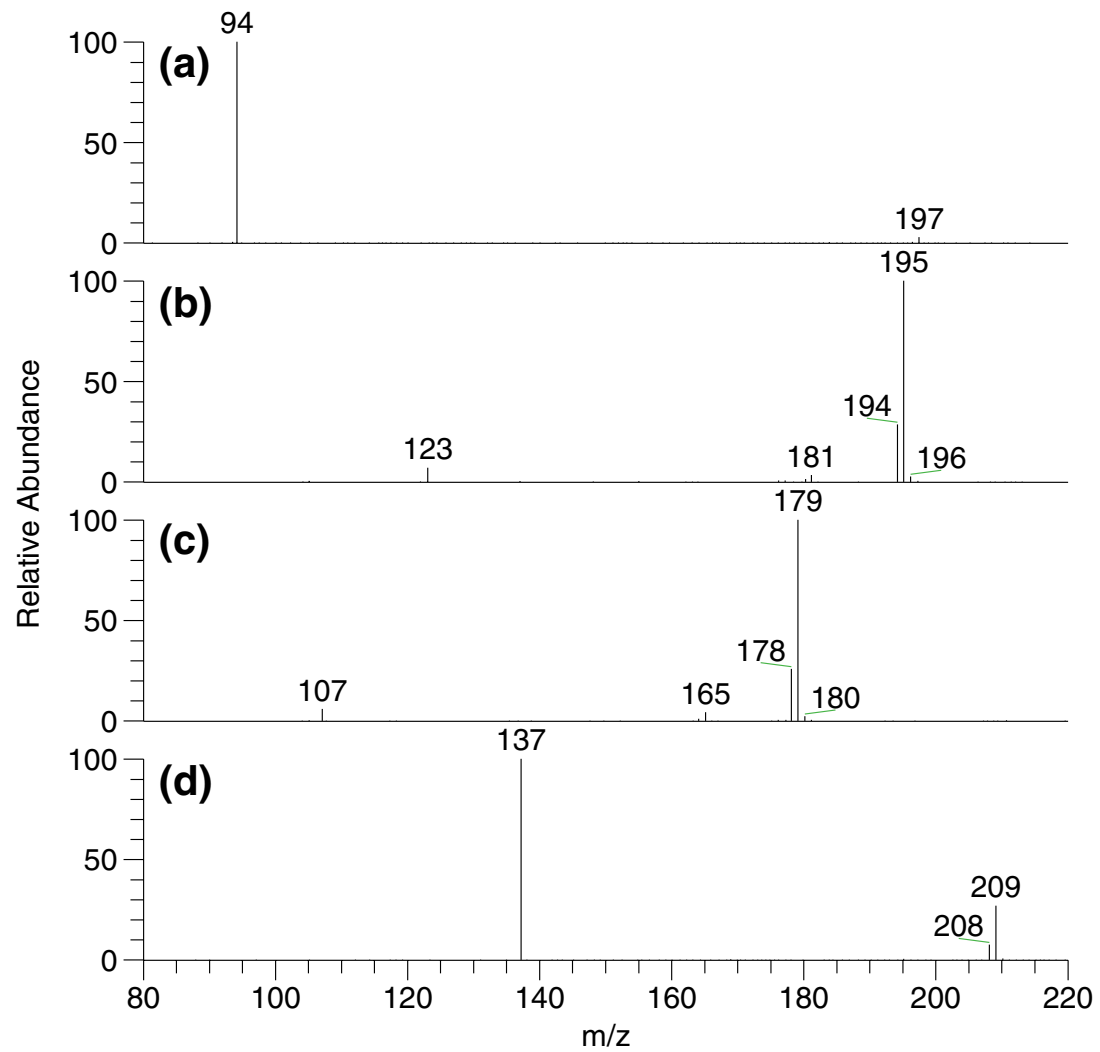

Figure 6. $M \mathrm{MS}^{2}$ spectra measured for each component [(a), aniline; (b), benzoic acid; (c), benzaldehyde; (d), methyl benzoate] of the test mixture separated by HPLC prior to MS analysis. The formation of the diagnostic product ions upon reactions of the protonated analytes are clearly visible in (b) $(\mathrm{m} / \mathrm{z} 195)$, (c) $(\mathrm{m} / \mathrm{z} 179)$, and (d) $(\mathrm{m} / \mathrm{z} 209)$ 


\section{Conclusions}

The ability to efficiently and effectively perform functional group selective ion-molecule reactions using TMB in both FTICR and LQIT mass spectrometers significantly bolsters the analytical utility of this methodology. Protonated oxygen-containing analytes were demonstrated to undergo a characteristic nucleophilic addition/elimination reaction upon exposure to TMB. Further, the functional group present in the analyte may be identified by isolating the diagnostic product ion of the ion-molecule reactions and subjecting it to CAD. Various oxygen-containing functionalities were shown to produce different fragment ions in this experiment. The results obtained using the LQIT instrument are almost identical to those obtained by using the FTICR, despite drastically different reaction conditions. The implementation of this experiment to LC-MS extends its applicability to the analysis of complex mixtures containing unknown oxygen-containing analytes.

\section{Acknowledgments}

The authors gratefully acknowledge the National Science Foundation for partial financial support of this work. S.C.H. acknowledges Fellowship support from the Department of Education through the Graduate Assistantships in Areas of National Need (GAANN) program. N.R.V. was supported as part of the Center for Direct Catalytic Conversion of Biomass to Biofuels (C3Bio), an Energy Frontier Research Center funded by the U.S. Department of Energy, Office of Science, Office of Basic Energy Sciences, Award Number DE-SC0000997.

\section{References}

1. Busch, K.L., Glish, G.L., McLuckey, S.A.: Mass Spectrometry/Mass Spectrometry: Techniques and Applications of Tandem Mass Spectrometry. VCH, New York (1988) pp. 173-277.

2. Sleno, L., Volmer, D.A.: Ion activation methods for tandem mass spectrometry. J. Mass Spectrom. 39, 1091-1230 (2004)

3. Lopez, L.L., Tiller, P.R., Senko, M.W., Schwartz, J.C.: Automated strategies for obtaining standardized collisionally induced dissociation spectra on a benchtop ion trap mass spectrometer. Rapid Commun. Mass Spectrom. 13, 663-668 (1999)

4. Clarke, N.J., Rindgen, D., Korfmacher, W.A., Cox, K.A.: Peer reviewed: systematic LC/MS metabolite identification in drug discovery. Anal. Chem. 73, 430A-439A (2001)

5. Dunn, W.B., Ellis, D.I.: Metabolomics: current analytical platforms and methodologies. TrAC Trends Anal. Chem. 24, 285-294 (2005)

6. Ermer, J., Vogel, M.: Applications of hyphenated LC-MS techniques in pharmaceutical analysis. Biomed. Chromatogr. 14, 373-383 (2000)

7. Wu, Y.H., Chen, X., Gier, L., Almarsson, O., Ostovic, D., Loper, A.E.: Identification of oxidative degradates of the thrombin inhibitor, 3-(2phenethylamino)-6-methyl-1-(2-amino-6-methyl-5-methylenecarboxamidomethylpyridinyl) pyrazinone, using liquid chromatography mass spectrometry and liquid chromatography tandem mass spectrometry. $J$. Pharm. Biomed. Anal. 20, 471-485 (1999)

8. Brodbelt, J.S.: Analytical applications of ion-molecule reactions. Mass Spectrom. Rev. 16, 91-110 (1997)

9. Eberlin, M.N.: Structurally diagnostic ion/molecule reactions: class and functional-group identification by mass spectrometry. J. Mass Spectrom. 41, 141-156 (2006)
10. Green, M.K., Lebrilla, C.B.: Ion-molecule reactions as probes of gasphase structures of peptides and proteins. Mass Spectrom. Rev. 16, 5371 (1997)

11. Gao, H., Petzold, C.J., Leavell, M.D., Leary, J.A.: Investigation of ionmolecule reactions as a quantification method for phosphorylated positional isomers: an FTICR approach. J. Am. Soc. Mass Spectrom. 14, 916-924 (2003)

12. Mosi, A.A., Cullen, W.R., Eigendorf, G.K.: Ion-molecule reactions of perfluorotributylamine (FC43) cations with polycyclic aromatic hydrocarbons in a quadrupole ion trap. Int. J. Mass Spectrom. 190/191, 195207 (1999)

13. Niemeyer, E.D., Brodbelt, J.S.: Isomeric differentiation of green tea catechins using gas-phase hydrogen-deuterium exchange reactions. $J$. Am. Soc. Mass Spectrom. 18, 1749-1759 (2007)

14. Zhang, J., Brodbelt, J.S.: Gas-phase hydrogen/deuterium exchange and conformations of deprotonated flavonoids and gas-phase acidities of flavonoids. J. Am. Chem. Soc. 126, 5906-5919 (2004)

15. Kenttämaa, H.I., Cooks, R.G.: Identification of protonated $\beta$-hydroxycarbonyl compounds by reactive collisions in tandem mass spectrometry. J. Am. Chem. Soc. 111, 4122-4123 (1989)

16. Meurer, E.C., Chen, H., Riter, L.S., Cooks, R.G., Eberlin, M.N.: Meerwein reaction of phosphonium ions with epoxides and thioepoxides in the gas phase. J. Am. Soc. Mass Spectrom. 15, 398-405 (2004)

17. Meurer, E.C., Sparrapan, R., Eberlin, M.N.: Gas-phase polar [4+2] cycloaddition with ethyl vinyl ether: a structurally diagnostic ionmolecule reaction for 2-azabutadienyl cations. J. Mass Spectrom. 38, 1075-1080 (2003)

18. Petzold, C.J., Leavell, M.D., Leary, J.A.: Screening and identification of acidic carbohydrates in bovine colostrum by using ion-molecule reactions and fourier transform ion cyclotron resonance mass spectrometry: specificity toward phosphorylated complexes. Anal. Chem. 76, 203-210 (2004)

19. Watkins, M.A., WeWora, D.V., Li, S., Winger, B.E., Kenttämaa, H.I.: Compound screening for the presence of the primary N-oxide functionality via ion-molecule reactions in a mass spectrometer. Anal. Chem. 77, 5311-5316 (2005)

20. Zhang, J., Ji, H., Sun, S., Mao, D., Liu, H., Guo, Y.: Selective determination of pyridine alkaloids in tobacco by PFTBA ions/analyte molecule reaction ionization ion trap mass spectrometry. J. Am. Soc. Mass Spectrom. 18, 1774-1782 (2007)

21. Cole, M.J., Enke, C.G.: Fast atom bombardment tandem mass spectrometry employing ion-molecule reactions for the differentiation of phospholipid classes. J. Am. Soc. Mass Spectrom. 2, 470-475 (1991)

22. Lennon, J.D.I.I.I., Cole, S.P., Glish, G.L.: Ion/molecule reactions to chemically deconvolute the electrospray ionization mass spectra of synthetic polymers. Anal. Chem. 78, 8472-8476 (2006)

23. Reid, G.E., O'Hair, R.A.J., Styles, M.L., McFadyen, W.D., Simpson, R.J.: Gas phase ion-molecule reactions in a modified ion trap: H/D exchange of noncovalent complexes and coordinatively unsaturated platinum complexes. Rapid Commun. Mass Spectrom. 12, 1701-1708 (1998)

24. Cooks, R.G., Chen, H., Eberlin, M.N., Zheng, X., Tao, W.A.: Polar acetalization and transacetalization in the gas phase: the Eberlin reaction. Chem. Rev. 106, 188-211 (2006)

25. Riter, L.S., Meurer, E.C., Handberg, E.S., Laughlin, B.C., Chen, H., Patterson, G.E., Eberlin, M.N., Cooks, R.G.: Ion/molecule reactions performed in a miniature cylindrical ion trap mass spectrometer. Analyst 128, 1112-1118 (2003)

26. Lee, S.-W., Lee, H.-N., Kim, H.S., Beauchamp, J.L.: Selective binding of crown ethers to protonated peptides can be used to probe mechanisms of H/D exchange and collision-induced dissociation reactions in the gas phase. J. Am. Chem. Soc. 120, 5800-5805 (1998)

27. Reid, G.E., Simpson, R.J., O'Hair, R.A.: Probing the fragmentation reactions of protonated glycine oligomers via multistage mass spectrometry and gas phase ion molecule hydrogen/deuterium exchange. Int. J. Mass Spectrom. 190/191, 209-230 (1999)

28. Campbell, K.M., Watkins, M.A., Li, S., Fiddler, M.N., Winger, B.E., Kenttämaa, H.I.: Functional group selective ion/molecule reactions: mass spectrometric identification of the amido functionality in protonated monofunctional compounds. J. Org. Chem. 72, 3159-3165 (2007)

29. Somuramasami, J., Duan, P., Watkins, M.A., Winger, B.E., Kenttämaa, H.I.: Ion-molecule reactions of trimethylborate allow the mass 
spectrometric identification and counting of functional groups in protonated bifunctional oxygen-containing compounds and polyols. Int. J. Mass Spectrom. 265, 359-371 (2007)

30. Watkins, M.A., Price, J.M., Winger, B.E., Kenttämaa, H.I.: Ionmolecule reactions for mass spectrometric identification of functional groups in protonated oxygen-containing monofunctional compounds. Anal. Chem. 76, 964-976 (2004)

31. Watkins, M.A., Winger, B.E., Shea, R.C., Kenttämaa, H.I.: Ionmolecule reactions for the characterization of polyols and polyol mixtures by ESI/FTICR mass spectrometry. Anal. Chem. 77, 13851392 (2005)

32. Gronert, S.: Quadrupole ion trap studies of fundamental organic reactions. Mass Spectrom. Rev. 24, 100-120 (2005)

33. O'Hair, R.A.J.: The 3D quadrupole ion trap mass spectrometer as a complete chemical laboratory for fundamental gas-phase studies of metal mediated chemistry. Chem. Commun. 1469-1481 (2006)

34. Waters, T., O'Hair, R.A.J., Wedd, A.G.: Catalytic gas phase oxidation of methanol to formaldehyde. J. Am. Chem. Soc. 125, 3384-3396 (2003)

35. Schwartz, J.C., Senko, M.W., Syka, J.E.P.: A two-dimensional quadrupole ion trap mass spectrometer. J. Am. Soc. Mass Spectrom. 13, 659669 (2002)
36. Habicht, S.C., Vinueza, N.R., Archibold, E.F., Duan, P., Kenttämaa, H. I.: Identification of the carboxylic acid functionality by using electrospray ionization and ion-molecule reactions in a modified linear quadrupole ion trap mass spectrometer. Anal. Chem. 80, 3416-3421 (2008)

37. Thomas, M.C., Mitchell, T.W., Harman, D.G., Deeley, J.M., Nealon, J. R., Blanksby, S.J.: Ozone-induced dissociation: elucidation of double bond position within mass-selected lipid ions. Anal. Chem. 80, 303-311 (2008)

38. Marshall, A.G., Wang, T.C.L., Ricca, T.L.: Tailored excitation for Fourier transform ion cyclotron resonance mass spectrometry. J. Am. Chem. Soc. 107, 7893-7897 (1985)

39. Gauthier, J.W., Trautman, T.R., Jacobson, D.B.: Sustained off-resonance irradiation for collision-activated dissociation involving Fourier transform ion cyclotron resonance mass spectrometry. Collision activated dissociation technique that emulates infrared multiphoton dissociation. Anal. Chim. Acta 246, 211-225 (1991)

40. Docks, E.L.: Kirk-Othmer Encyclopedia of Chemical Technology, pp. 413-423. Wiley, New York (1992)

41. Gronert, S., O'Hair, R.A.J.: Gas phase reactions of trimethyl borate with phosphates and their noncovalent complexes. J. Am. Soc. Mass Spectrom. 13, 1088-1098 (2002) 